\title{
Investigation of tool wear, surface roughness, sound intensity, and power consumption during hard turning of AISI 4140 steel using multilayer-coated carbide inserts
}

\author{
Abidin Şahinoğlu* and Mohammad Rafighi** \\ * Department of Machine and Metal Technology, Manisa Celal Bayar University, Manisa, Turkey \\ ** Department of Mechanical Engineering, University of Turkish Aeronautical Association, Ankara, Turkey \\ *Corresponding Author : abidinsahinoglu@gmail.com
}

Submitted : 10/10/2019

Revised $\quad: 15 / 10 / 2020$

Accepted :03/11/2020

\begin{abstract}
The present study investigated the machinability aspects, namely, surface roughness, sound intensity, power consumption, and crater wear, during dry turning of hardened AISI 4140 steel (63 HRC) employing $\left(\mathrm{TiCN} / \mathrm{Al}_{2} \mathrm{O}_{3} / \mathrm{TiN}\right)$ multilayer-coated carbide inserts under dry cutting condition. The relationship between machining parameters and output parameters was determined using the Taguchi design. The analysis of variance was employed to evaluate the contributions of input parameters on output parameters. The main effect plots illustrated the impacts of cutting speed, feed, and depth of cut on response variables. Results show that the feed was the most dominant factor that affects surface roughness. Increasing the feed value increases the surface roughness, power consumption, and sound intensity. In the other part of this study, the constant values for feed $(0.3 \mathrm{~mm} / \mathrm{rev})$, depth of cut $(0.7 \mathrm{~mm})$, and cutting speed $(150 \mathrm{~m} / \mathrm{min})$ have been selected to evaluate a tool life that has $0.3 \mathrm{~mm}$ crater wear criteria. The results indicated that multilayer-coated carbide inserts presented very good tool life and reached $0.3 \mathrm{~mm}$ in $90 \mathrm{~min}$. The experimental study results showed that chipping and abrasion were found to be the significant wear mechanism during hard turning of AISI 4140 steel. The cutting speed was the most significant parameter on the tool wear, although high cutting speed results the good surface finish but adversely increases the tool crater wear.
\end{abstract}

Keywords: AISI 4140 steel; Surface roughness; Power consumption, Multilayer-coated carbide; Tool wear.

\section{INTRODUCTION}

One of the most important purposes of machining industries is to manufacture products with high dimensional accuracy and high quality by reducing the cost and process time in this competitive world. In addition, environmental pollutions are another significant aspect that should be considered by decreasing power consumption and cutting fluids that adversely affect the ecology's cleanliness. Nowadays, in most machining operations, hard turning with coating cutting inserts was established as an essential process on steels to deal with the issues mentioned above. 
In hard turning applications, the metal workpieces' hardness is in the range of 40-70 HRC (Bartarya and Choudhury 2012). Hard turning is used in the production of many parts, especially in automotive industries such as gears, bearings, and shafts. The advantages of hard turning compared to conventional machining processes are higher productivity, lower energy consumption, shorter setup time, better surface quality, and lower manufacturing costs (Yallese et al., 2009; Guo and Liu 2002; Tönshoff et al., 2000). Cutting tools play a crucial role in enhancing the products' productivity and quality besides minimizing the machining process's cost. The hard turning processes are usually performed using cubic boron nitride $(\mathrm{CBN})$, ceramic or multilayer-coated carbide inserts with high wear resistance and hardness. A titanium-based coated cutting tool is frequently used in hard turning due to its good wear resistance, low friction coefficient, high thermal conductivity, and corrosion properties. Chemical vapour deposition (CVD) and physical vapour deposition (PVD) techniques are applied to cutting tool materials to obtain coated cutting inserts (Das et al., 2018).

Tool wear is one of the critical issues in hard turning due to its effects on surface quality and integrity, dimensional accuracy of the component, residual stresses, and tool life. Previous studies revealed that the depth of cut and cutting speed affected tool life significantly (Rakesh and Datta 2019; Mia et al., 2018; Das et al., 2018; Salimi Asl et al., 2017). Any increase in each cutting parameter increases cutting forces and temperatures. The high temperature is one of the parameters that result in tool wear (Salimiasl and Rafighi 2017).

Surface roughness is another vital issue that affects the wear rate, fatigue strength, corrosion resistance, and tribological properties of the machined surface. Recently, many studies were performed to explore the effects of coated cutting inserts during hard turning of different steels since the tool wear modifies both the surface and tool life ( Rakesh and Datta 2019; Das et al., 2018; Mia et al., 2018).

Several factors such as cutting parameters, workpiece, and tool variables affect the surface roughness and tool wear in the hard turning process (Salimiasl and Rafighi 2017; Patel and Gandhi 2019; Sarnobat and Raval 2019). Cutting parameters consist of feed rate, cutting speed, and depth of cut. Workpiece variables consist of hardness and material of the component. Tool variables consist of tool nose radius, tool material, tool point angle, cutting edge geometry, and tool coating. Previous studies have shown that coating is an effective method to increase the tool wear resistance and decrease the tool cost in machining industries (Zhao and Lio 2020; Moganapriya et al., 2018; Keblouti et al., 2017). The $\mathrm{TiCN}, \mathrm{Al}_{2} \mathrm{O}_{3}$, and $\mathrm{TiN}$ are the most frequently used material for a coating with wear resistance, thermal barrier, and lubricity properties. It is important to select the most appropriate machining parameters in the hard turning operations to obtain high-quality products with minimum production cost. In past years, the optimization of cutting parameters is fulfilled by using the experimental results and developing a mathematical model to increase productivity.

In this study, the influences of process parameters such as feed, depth of cut, and cutting speed on output variables, namely, sound intensity, surface roughness, power consumption, and tool wear, are investigated. Hard turning is performed on AISI 4140 steel (63 HRC) employing multilayer-coated carbide cutting inserts under a dry cutting environment. The chemical vapour deposition (CVD) was applied to coat the carbide insert with thin layers of titanium carbide nitride $(\mathrm{TiCN})$, aluminum oxide $\left(\mathrm{Al}_{2} \mathrm{O}_{3}\right)$, and titanium nitride $(\mathrm{TiN})$. Thin coating layers can decrease the tool wear and increase the tool life (Nouari et al., 2003; Moganapriya et al., 2018; Keblouti et al., 2017). The analysis of variance and the main effect plots are employed to evaluate the influences of machining variables on output parameters. Also, mathematical models are developed to predict the tool wear.

\section{LITERATURE REVIEW}

Many experimental works are performed to investigate the impacts of different process conditions on surface roughness and tool wear during hard turning of various steels (Das et al., 2018; Mia et al., 2018; Patel and Gandhi 
2019; Sarnobat and Raval 2019; Kuntoğlu and Sağlam 2020). However, the number of studies investigating the impacts of cutting variables on power consumption and sound intensity is limited (Şahinoğlu and Rafighi 2020 $\mathrm{a}, \mathrm{b})$. The following literature review is related to the study of process conditions such as tool variables and cutting conditions on the response variables, as mentioned above.

Aslantaş et al. investigated the effects of $\mathrm{Al}_{2} \mathrm{O}_{3} / \mathrm{TiCN}$ mixed ceramic tools coated with $\mathrm{TiN}$ on surface roughness, tool wear, and tool life while turning hardened AISI 52100 bearing steel. The results presented that uncoated cutting tools are vulnerable to fracture; however, the more obvious damage in TiN coated inserts is crater wear (Aslantas et al., 2012).

In Huang's study, the optimization of machining parameters was performed to model the CBN inserts crater wear rate during hard turning of AISI 52100 bearing steel. The CBN cutting tools are expensive, and the need for maximizing tool life during the manufacturing process is indispensable. Therefore, the results showed that adhesion is the dominant factor for tool wear, among other factors such as diffusion and abrasion. Further, the mathematical model presents good agreement between experimental and predicted results (Huang and Dawson 2005; Huang and Liang 2004).

In other studies, the impacts of wiper-coated carbide insert on tool life and surface roughness while turning hardened AISI 420 stainless steel were investigated. The results showed that increasing the cutting speed and feed decrease tool life. Further, the fine surface quality is achieved using wiper-coated carbide inserts compared to conventional inserts (Kurniawan et al., 2010; Noordin et al., 2007).

The impacts of machining variables on the cutting forces and surface roughness during turning of hardened AISI 52100 bearing steel using cubic boron nitride cutting tools were evaluated (Bouacha et al., 2010). Results showed that feed has a dominant influence on the surface roughness. The same results were obtained for surface roughness while turning hardened AISI 4140 steel employing $\mathrm{Al}_{2} \mathrm{O}_{3} / \mathrm{TiC}$ inserts (Asiltürk and Akkuş 2011).

Motorcu reported the influences of tool nose radius and cutting parameters such as feed rate, depth of cut and cutting speed on surface quality while performing hard turning on AISI 8660 steel using physical vapour deposition coated ceramic inserts. The significant parameters on surface roughness were determined using analysis of variance (ANOVA). According to the results, feed is the dominant variable on surface roughness. Both depths of cut and tool nose radius affect surface roughness (Motorcu 2010).

Meddour et al. showed the impacts of input parameters such as feed, tool nose radius, depth of cut, and cutting speed on the cutting forces and surface roughness. The turning process was performed on hardened AISI 52100 bearing steel with 59 HRC employing the ceramic cutting inserts. Taguchi method was used to model the output parameters, while the influences of process variables on output parameters were determined using ANOVA. The results showed the maximum effect of depth of cut on the cutting forces. However, the tool nose radius and feed have a significant impact on surface roughness. A combination of low feed and large nose radius improves the surface quality dramatically (Meddour et al., 2015).

Sahoo performed a hard turning process on AISI 4340 steel by employing uncoated and multilayer-coated carbide inserts to evaluate process parameters' influences on surface roughness, cutting forces, chip morphology, and flank wear. According to this study's results, the tool operating time without failure for $\mathrm{ZrCN}$ and TiN coated carbide cutting tools is approximately $8 \mathrm{~min}$ and $19 \mathrm{~min}$. Thus, the multilayer-coated insert ( TiN/TiCN $/ \mathrm{Al}_{2} \mathrm{O}_{3} / \mathrm{TiN}$ ) exhibits excellent performance in comparison to uncoated and coated carbide insert (TiN/TiCN $/ \mathrm{Al}_{2} \mathrm{O}_{3} / \mathrm{ZrCN}$ ) in evaluating of the flank wear (Sahoo and Sahoo 2012). 
Elbah et al. compared the effects of the conventional inserts and wiper inserts on tool wear and surface roughness during turning hardened AISI 4140 steel. The analysis of variance was used to determine the dominant factors affecting the output parameters, and the validation of the quadratic regression model was done by using response surface methodology. According to the results, the feed rate was the most important factor influencing surface roughness. Comparing conventional ceramic cutting inserts and wiper ceramic cutting insert reveals that wiper ceramic creates a better surface finish in the specimen (Elbah et al., 2013).

Although the number of studies that exhibited the impacts of various tools on surface quality and tool life and while turning hardened steels are high, a few papers are published relative to multilayer-coated carbide inserts' performance on surface roughness, sound intensity, power consumption, and tool wear simultaneously. Mainly, the number of studies that considered sound intensity as criteria for machining operation is limited. In this study, feed, depth of cut, and cutting speed are chosen as process parameters, and sound intensity, surface roughness, power consumption, and tool wear are chosen as response variables. Hard turning is performed on AISI 4140 steel employing multilayer-coated carbide inserts $\left(\mathrm{TiCN} / \mathrm{Al}_{2} \mathrm{O}_{3} / \mathrm{TiN}\right)$. The results are evaluated using main effect plots, and the significant factors are determined through an analysis of variance.

\section{EXPERIMENTAL PROCEDURES}

\section{Cutting Conditions}

This experimental study is performed to evaluate surface roughness $(\mathrm{Ra})$, sound intensity, tool wear, and power consumption during turning of hardened AISI 4140 steel employing multilayer-coated carbide inserts under dry cutting conditions. Three cutting parameters, namely feed (f), cutting speed (V), and depth of cut (a), were chosen according to the previous studies and manufacturer catalogue for this material and inserts. These cutting parameters are given in Table 1.

Table 1. The levels of cutting parameters.

\begin{tabular}{|c|c|c|c|c|c|c|c|c|c|}
\hline \multirow{2}{*}{ Parameters-(symbol) } & \multicolumn{2}{|c|}{ Depth of cut- $(a)$} & \multicolumn{2}{c|}{ Cutting speed-( $(V)$} & \multicolumn{2}{c|}{ Feed-( $f)$} \\
\hline Units & \multicolumn{2}{|c|}{$(\mathrm{mm})$} & \multicolumn{2}{|c|}{ (mm/min) } & \multicolumn{2}{c|}{$(\mathrm{mm} / \mathrm{rev})$} \\
\hline Levels & 0.3 & 0.5 & 0.7 & 100 & 125 & 150 & 0.1 & 0.2 & 0.3 \\
\hline
\end{tabular}

\section{Machine and Cutting Tool}

The dry turning is performed on the TAKSAN CNC lathe (TTC-630 model). This lathe has $20 \mathrm{~kW}$ power and 4000 RPM spindle speed capacities. 
In this test, multilayer-coated carbide inserts manufactured by Taegutec with WNMG 080408 MT TT5100 ISO designation are used. The chemical vapour deposition (CVD) is used to coat carbide inserts with $\mathrm{TiCN} / \mathrm{Al}_{2} \mathrm{O}_{3} / \mathrm{TiN}$ layers. It has a $0.8 \mathrm{~mm}$ tool nose radius $(\mathrm{r}), 4.76 \mathrm{~mm}$ thickness $(\mathrm{t}), 12.70 \mathrm{~mm}$ inscribed diameter (d), and negative $80^{\circ}$ cutting tip. Besides, the cutting tools are rigidly mounted into chuck using the MWLNR 2525 M08 tool holder.

\section{Experiment Specimen}

The AISI 4140 steel workpiece has $200 \mathrm{~mm}$ length and $45 \mathrm{~mm}$ diameter. Heat treatment is applied at $920^{\circ} \mathrm{C}$ to increase the hardness of material to 63 (HRC), and then it is quenched in the oil for $30 \mathrm{~min}$. Moreover, the tempering process is applied for $150 \mathrm{~min}$ at $400^{\circ} \mathrm{C}$ to remove the residual stresses; hence, the homogeneous structure is obtained. Table 2 shows the chemical composition of AISI 4140.

Table 2. Chemical composition of AISI 4140 steel.

\begin{tabular}{|l|c|c|c|c|c|c|c|c|}
\hline Element & $\mathrm{C}$ & $\mathrm{Mn}$ & $\mathrm{Si}$ & $\mathrm{Mo}$ & $\mathrm{Cr}$ & $\mathrm{S}_{\max }$ & $\mathrm{P}_{\max }$ & $\mathrm{Fe}$ \\
\hline Content (\%) & $0.39-0.44$ & $0.65-0.95$ & $0.15-0.35$ & $0.12-0.32$ & $0.85-1.15$ & 0.040 & 0.035 & Balance \\
\hline
\end{tabular}

\section{Measurement Devices}

Mitutoyo SJ 201 portable device was employed to measure the arithmetic average surface roughness (Ra) of the test specimen. It has a cut-off length of $0.8 \mathrm{~mm}$. The calibration of this device was done employing a standard calibration block. The final surface roughness value was considered the mean value of the three measured roughnesses from various locations on the workpiece.

Lutron SL-401 portable device was used to measure sound intensity. In order to avoid possible instantaneous fluctuations in the sound intensity, this device was located $1 \mathrm{~m}$ away from the CNC lathe machine.

UNI-T UT201 device was used to measure the machine's current. The total current value is calculated by multiplying the current value of one phase by three. Subsequently, the power consumption was obtained by multiplying the voltage by the total current value.

Optical microscope (AM4815T Dino-Lite Edge) with a magnification of 220 times equipped with digital camera and computer was used to measure the tool wear. The crater wear happens in the area of cutting edge. Therefore, the cutting edge has the maximum crater wear. The experimental setup is given in Figure 1. 


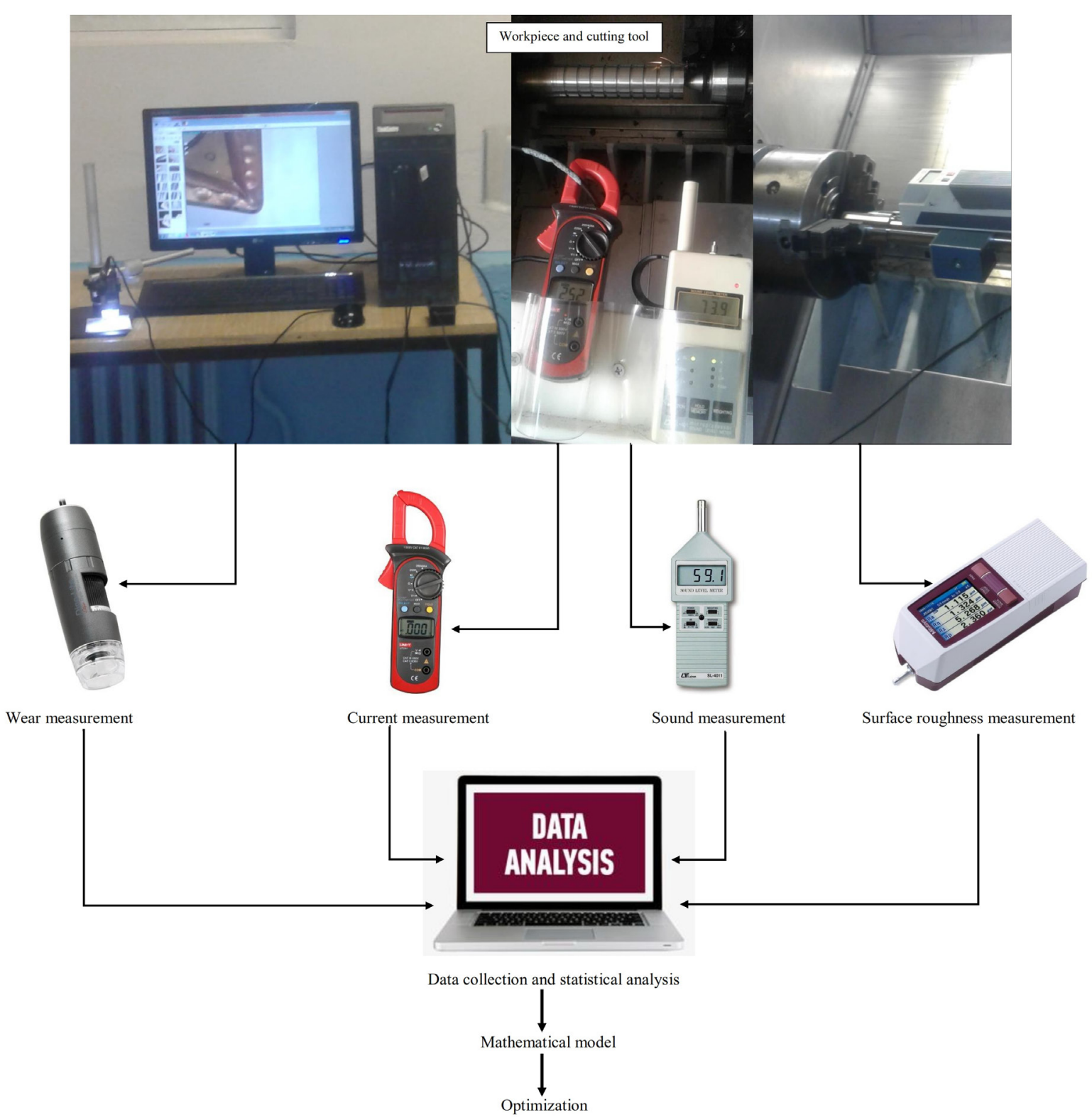

Figure 1. Schematic of the experimental setup.

\section{RESULTS AND DISCUSSION}

In this section, the effect of machining parameters on sound intensity, power consumption, and surface roughness during hard turning of AISI 4140 steel employing multilayer-coated carbide insert presented. The relation between machining parameters and output parameters is determined using the regression equation. The most significant factors that influenced the response parameters are shown using analysis of variance. The effects of machining parameters on machinability aspects are depicted using main effect plots. Finally, the regression model was developed to predict the tool wear. 


\section{Experimental Study Results}

In the presented work, the $\mathrm{L}_{27}$ Taguchi design was utilized to create a relationship between input and output parameters. The experimental results for sound intensity, power consumption, and surface roughness for different combinations of machining parameters obtained from Taguchi design are presented in Table 3. The power consumption was obtained in the range of (1914-4560.6) W, the sound intensity was obtained in the range of (76.1-89) $\mathrm{dB}$, and the range of the surface roughness was $(0.375-2.49) \mu \mathrm{m}$. According to the results, the minimum power consumption was obtained at the combination of $0.1(\mathrm{~mm} / \mathrm{rev})$ feed, $100(\mathrm{~m} / \mathrm{min})$ cutting speed, and 0.3 $(\mathrm{mm})$ depth of cut and. The minimum surface roughness was obtained at the combination of $0.2(\mathrm{~mm} / \mathrm{rev})$ feed, $0.7(\mathrm{~mm})$ depth of cut, and $125(\mathrm{~m} / \mathrm{min})$ cutting speed. The minimum sound intensity was obtained at the combination of $0.7(\mathrm{~mm})$ depth of cut, $150(\mathrm{~m} / \mathrm{min})$ cutting speed, and $0.1(\mathrm{~mm} / \mathrm{rev})$ feed.

Table 3. Experimental results for surface roughness, power consumption, and sound intensity.

\begin{tabular}{|c|c|c|c|c|c|c|}
\hline 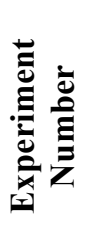 & 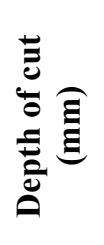 & 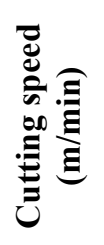 & 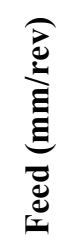 & 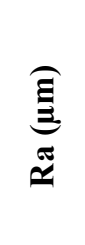 & 离总 & 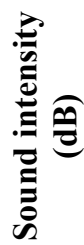 \\
\hline 1 & 0.3 & 100 & 0.1 & 0.59 & 1914 & 81.6 \\
\hline 2 & 0.3 & 100 & 0.2 & 0.75 & 2046 & 82.4 \\
\hline 3 & 0.3 & 100 & 0.3 & 1.47 & 2151 & 83.2 \\
\hline 4 & 0.3 & 125 & 0.1 & 0.67 & 1986 & 78 \\
\hline 5 & 0.3 & 125 & 0.2 & 0.84 & 2171 & 80 \\
\hline 6 & 0.3 & 125 & 0.3 & 1.46 & 2329 & 81 \\
\hline 7 & 0.3 & 150 & 0.1 & 0.51 & 2171 & 77 \\
\hline 8 & 0.3 & 150 & 0.2 & 0.75 & 2395 & 79.2 \\
\hline 9 & 0.3 & 150 & 0.3 & 1.16 & 2620 & 79.6 \\
\hline 10 & 0.5 & 100 & 0.1 & 0.6 & 2013 & 81 \\
\hline 11 & 0.5 & 100 & 0.2 & 1.44 & 2244 & 85 \\
\hline 12 & 0.5 & 100 & 0.3 & 2.43 & 2620 & 89 \\
\hline 13 & 0.5 & 125 & 0.1 & 0.61 & 2290 & 80 \\
\hline 14 & 0.5 & 125 & 0.2 & 1.33 & 2574 & 81.9 \\
\hline 15 & 0.5 & 125 & 0.3 & 2.49 & 2818 & 85 \\
\hline 16 & 0.5 & 150 & 0.1 & 0.55 & 2468 & 79 \\
\hline 17 & 0.5 & 150 & 0.2 & 1.30 & 2778 & 81 \\
\hline 18 & 0.5 & 150 & 0.3 & 1.63 & 3069 & 83 \\
\hline 19 & 0.7 & 100 & 0.1 & 0.64 & 2574 & 82.1 \\
\hline 20 & 0.7 & 100 & 0.2 & 1.05 & 2917 & 83.5 \\
\hline 21 & 0.7 & 100 & 0.3 & 0.98 & 3234 & 86.6 \\
\hline 22 & 0.7 & 125 & 0.1 & 0.39 & 3141 & 78.9 \\
\hline 23 & 0.7 & 125 & 0.2 & 0.37 & 3445 & 76.2 \\
\hline 24 & 0.7 & 125 & 0.3 & 0.56 & 3570 & 80.3 \\
\hline 25 & 0.7 & 150 & 0.1 & 0.6 & 3491 & 76.1 \\
\hline 26 & 0.7 & 150 & 0.2 & 0.56 & 4026 & 77 \\
\hline 27 & 0.7 & 150 & 0.3 & 0.82 & 4560 & 78.9 \\
\hline
\end{tabular}




\section{Analysis Of Variance}

Analysis of variance is performed to define the impacts of machining variables on response parameters. In this experimental work, the analysis of variance is performed using Minitab-19 software. Table 4 shows the results of ANOVA for surface roughness. According to the results, feed is the most significant factor that affects surface roughness by $42.30 \%$ contribution. Following the feed rate, depth of cut is the next critical factor on the surface roughness with a $28.70 \%$ contribution effect. The interaction of feed rate and depth of cut with $17.66 \%$ contribution is also exhibited high impact on the surface quality. Cutting speed has a minor effect on the response.

Table 4. ANOVA results for surface roughness.

\begin{tabular}{|c|c|c|c|c|c|c|c|}
\hline Source & DOF & Seq SS & Adj SS & Adj MS & F-Value & P-Value & Contribution \\
\hline $\mathrm{a}$ & 2 & 2.3453 & 2.3453 & 1.17263 & 43.74 & 0.000 & $28.70 \%$ \\
\hline $\mathrm{V}$ & 2 & 0.2394 & 0.2394 & 0.11968 & 4.46 & 0.050 & $2.93 \%$ \\
\hline $\mathrm{f}$ & 2 & 3.4567 & 3.4567 & 1.72836 & 64.46 & 0.000 & $42.30 \%$ \\
\hline $\mathrm{a} * \mathrm{~V}$ & 4 & 0.3265 & 0.3265 & 0.08162 & 3.04 & 0.084 & $4.00 \%$ \\
\hline $\mathrm{a} * \mathrm{f}$ & 4 & 1.4431 & 1.4431 & 0.36077 & 13.46 & 0.001 & $17.66 \%$ \\
\hline $\mathrm{V} * \mathrm{f}$ & 4 & 0.1466 & 0.1466 & 0.03666 & 1.37 & 0.327 & $1.79 \%$ \\
\hline Error & 8 & 0.2145 & 0.2145 & 0.02681 & & & $2.62 \%$ \\
\hline Total & 26 & 8.1720 & & & & & $100.00 \%$ \\
\hline
\end{tabular}

Table 5 shows the results of ANOVA for power consumption. According to the results, the depth of cut has a significant influence on power consumption by $64.83 \%$ contribution. Following to depth of cut, cutting speed and feed are the next important parameters with $16.81 \%$ and $11.80 \%$ contribution, respectively. The interaction of depth of cut and cutting speed presents a $4.49 \%$ contribution effect on the power consumption.

Table 5. ANOVA results for power consumption.

\begin{tabular}{|c|c|c|c|c|c|c|c|}
\hline Source & DOF & Seq SS & Adj SS & Adj MS & F-Value & P-Value & Contribution \\
\hline $\mathrm{a}$ & 2 & 7399480 & 7399480 & 3699740 & 485.80 & 0.000 & $64.83 \%$ \\
\hline $\mathrm{V}$ & 2 & 1918669 & 1918669 & 959334 & 125.97 & 0.000 & $16.81 \%$ \\
\hline $\mathrm{f}$ & 2 & 1346995 & 1346995 & 673497 & 88.43 & 0.000 & $11.80 \%$ \\
\hline $\mathrm{a} * \mathrm{~V}$ & 4 & 512077 & 512077 & 128019 & 16.81 & 0.001 & $4.49 \%$ \\
\hline $\mathrm{a} * \mathrm{f}$ & 4 & 110847 & 110847 & 27712 & 3.64 & 0.057 & $0.97 \%$ \\
\hline $\mathrm{V} * \mathrm{f}$ & 4 & 63887 & 63887 & 15972 & 2.10 & 0.173 & $0.56 \%$ \\
\hline Error & 8 & 60926 & 60926 & 7616 & & & $0.53 \%$ \\
\hline Total & 26 & 11412881 & & & & & $100.00 \%$ \\
\hline
\end{tabular}


Table 6 shows the ANOVA results for sound intensity. These results indicated that all cutting parameters, namely, cutting speed, feed rate, and depth of cut, are significant factors for sound intensity by $45.06 \%, 24.00 \%$, and $16.97 \%$ contribution, respectively. Besides, the interaction of $(a * f)$ also has a significant impact on the response.

Table 6. ANOVA results for sound intensity.

\begin{tabular}{|c|c|c|c|c|c|c|c|}
\hline Source & DOF & Seq SS & Adj SS & Adj MS & F-Value & P-Value & Contribution \\
\hline $\mathrm{a}$ & 2 & 43.343 & 43.343 & 21.6715 & 25.43 & 0.000 & $16.97 \%$ \\
\hline $\mathrm{V}$ & 2 & 115.067 & 115.067 & 57.5337 & 67.50 & 0.000 & $45.06 \%$ \\
\hline $\mathrm{f}$ & 2 & 61.290 & 61.290 & 30.6448 & 35.95 & 0.000 & $24.00 \%$ \\
\hline $\mathrm{a} * \mathrm{~V}$ & 4 & 10.944 & 10.944 & 2.7359 & 3.21 & 0.075 & $4.29 \%$ \\
\hline $\mathrm{a} * \mathrm{f}$ & 4 & 13.661 & 13.661 & 3.4154 & 4.01 & 0.045 & $5.35 \%$ \\
\hline $\mathrm{V} * \mathrm{f}$ & 4 & 4.217 & 4.217 & 1.0543 & 1.24 & 0.369 & $1.65 \%$ \\
\hline Error & 8 & 6.819 & 6.819 & 0.8523 & & & $2.67 \%$ \\
\hline Total & 26 & 255.341 & & & & & $100.00 \%$ \\
\hline
\end{tabular}

\section{Main Effect Plots}

Figure 2 depicts the main effect plot for the surface roughness values. The plot indicated that feed is the most dominant factor that influences the surface roughness. By increasing the feed value, the surface roughness value also increases sharply. The same results were found in Bouacha, Aslitürk, Motorcu and Şahinoğlu studies (Asiltürk and Akkuş 2011; Motorcu 2010; Bouacha et al., 2010; Şahinoğlu and Rafighi 2020a). According to the main effect plot, surface roughness slightly decreases as cutting speed increases. Further, the depth of cut has a great impact on surface roughness. However, the minimum value can be obtained with a combination of high cutting speed, low feed rate and low depth of cut.

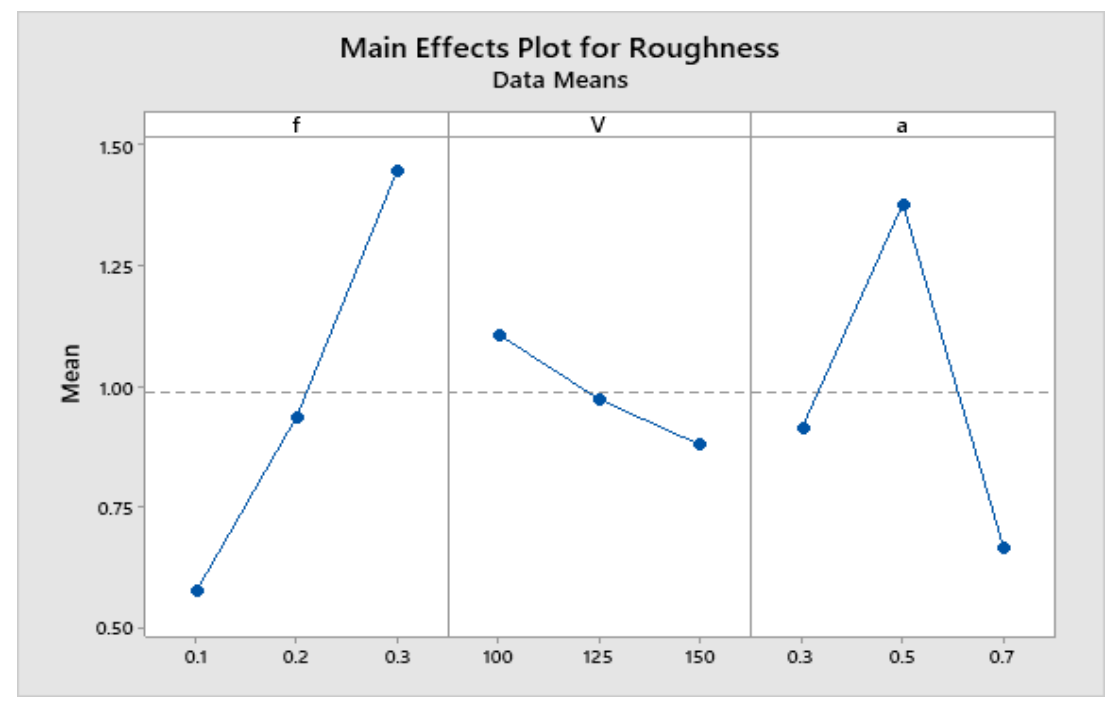

Figure 2. Main effect plot for surface roughness $(\mu \mathrm{m})$. 
Figure 3 shows the main effect plot for power consumption. Any increase in the amount of all machining parameters increases the power consumption. However, the depth of cut causes a significant increase in power consumption. This phenomenon is applying maximum load on the CNC lathe while turning the workpiece at 0.7 mm depth of cut.

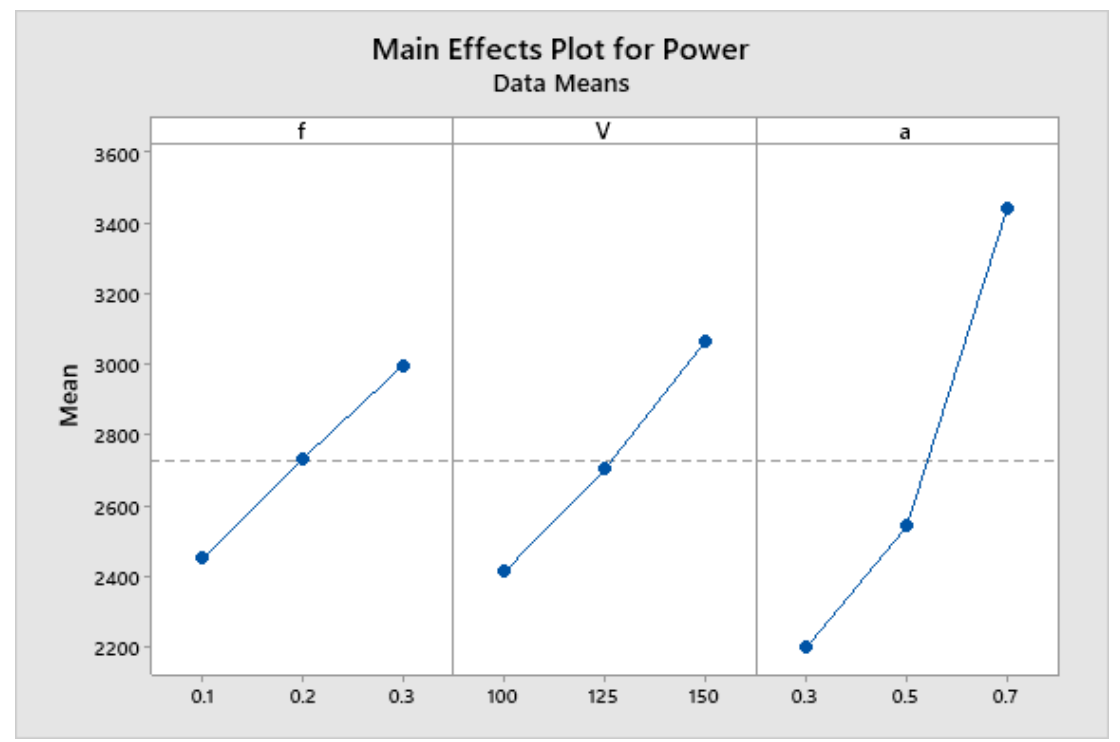

Figure 3. Main effect plot for power consumption (W).

The main effect plot for the sound intensity is illustrated in Figure 4. This plot showed that the sound intensity decreases sharply by any increase in the cutting speed. The high cutting speed reduces the cutting forces, and consequently, the load on the machine decreases, which causes a lower sound. The feed rate is the next important factor that increases the sound intensity while it increases.

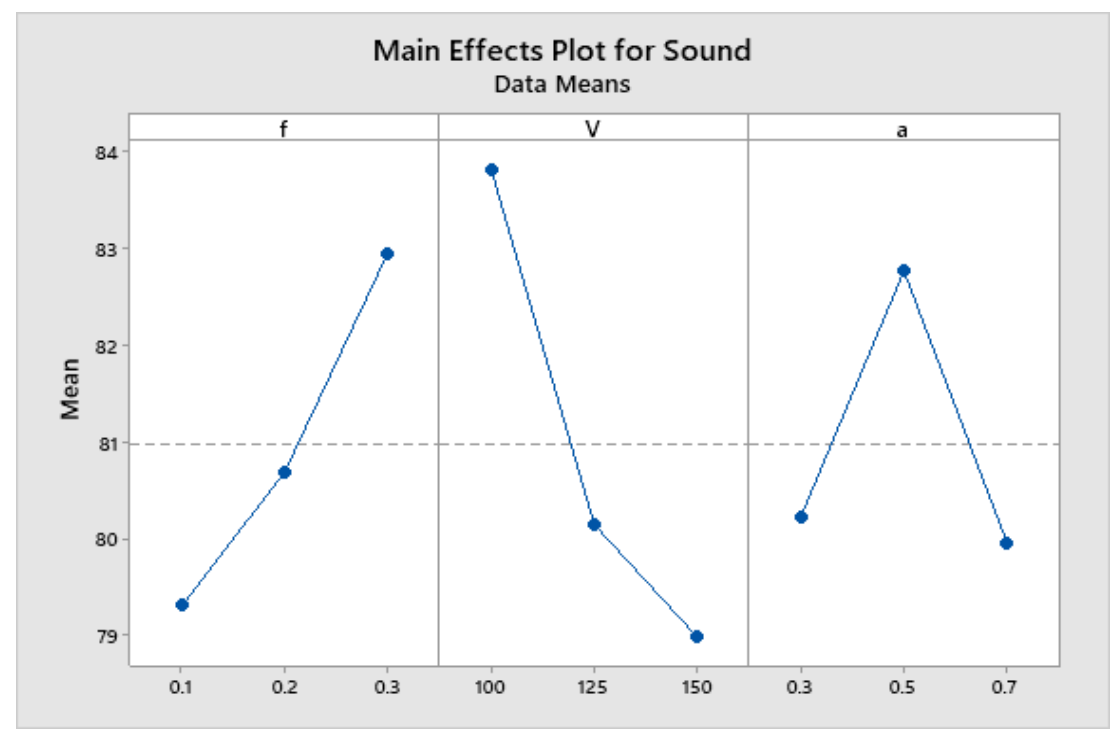

Figure 4. Main effect plot for sound intensity (dB). 


\section{Repeatability Test}

Before the final run for this experimental work, three sets of cutting parameters were chosen for the repeatability test. The experimental errors for the repeating trials are presented in Table 7 . According to the results, the error percentage between experimental and measurement results for surface roughness, power consumption, and sound intensity is in the range of $(2.25-3.65 \%),(1.38-2.44 \%)$, and $(0-0.13 \%)$, respectively.

Table 7. Repeatability test before the final run.

\begin{tabular}{|c|c|c|c|c|c|c|c|c|c|c|c|c|}
\hline & \multicolumn{3}{|c|}{$\begin{array}{c}\text { Cutting } \\
\text { parameters }\end{array}$} & \multicolumn{3}{|c|}{ Surface roughness $(\mu \mathrm{m})$} & \multicolumn{3}{|c|}{ Power consumption (W) } & \multicolumn{3}{|c|}{ Sound intensity $(\mathrm{dB})$} \\
\hline & $a$ & $V$ & $f$ & $\begin{array}{c}\text { Final } \\
\text { run }\end{array}$ & $\begin{array}{c}\text { Repeating } \\
\text { test }\end{array}$ & $\begin{array}{c}\text { Error } \\
(\%)\end{array}$ & $\begin{array}{c}\text { Final } \\
\text { run }\end{array}$ & $\begin{array}{c}\text { Repeating } \\
\text { test }\end{array}$ & $\begin{array}{c}\text { Error } \\
(\%)\end{array}$ & $\begin{array}{l}\text { Final } \\
\text { run }\end{array}$ & $\begin{array}{c}\text { Repeating } \\
\text { test }\end{array}$ & $\begin{array}{c}\text { Error } \\
(\%)\end{array}$ \\
\hline 1 & 0.3 & 100 & 0.1 & 0.59 & 0.61 & 3.39 & 1914 & 1950 & 1.84 & 81.6 & 81.5 & 0.12 \\
\hline 2 & 0.5 & 125 & 0.2 & 1.33 & 1.30 & 2.25 & 2574 & 2637 & 2.44 & 81.9 & 81.9 & 0 \\
\hline 3 & 0.7 & 150 & 0.3 & 0.82 & 0.79 & 3.65 & 4560 & 4497 & 1.38 & 78.9 & 79.0 & 0.13 \\
\hline
\end{tabular}

\section{Optimization of Machining Parameter}

The optimization of machining parameters in the manufacturing process is difficult due to the existence of many factors. However, it is essential to specify the optimum machining variables to minimize machining costs and maximize surface and tool life quality. Table 8 presents the machining parameters and their responses calculated through the mean value for each input parameter. The optimum machining parameters correspond to the lowest value for each response. For instance, the average of the surface roughness for the first level $(0.1$ $\mathrm{mm} / \mathrm{rev}$ ) of the feed rate is obtained using the Equation (1):

$$
\frac{(0.59+0.675+0.51+0.6+0.61+0.55+0.64+0.395+0.6)}{9}=0.5744 \mu \mathrm{m}
$$

Thus, minimum surface roughness and sound intensity can be obtained using the first level of feed rate (0.1 $\mathrm{mm} / \mathrm{rev})$, third level of cutting speed $(150 \mathrm{~m} / \mathrm{min})$, and third level of depth of cut $(0.5 \mathrm{~mm})$. Minimum power consumption can be obtained using the first level of all machining parameters. 
Table 8. Optimum machining parameters and their levels.

\begin{tabular}{|c|c|c|c|c|c|c|c|c|c|}
\hline & \multicolumn{2}{|c|}{ Surface roughness $(\mu \mathrm{m})$} & \multicolumn{2}{c|}{ Power consumption (W) } & \multicolumn{3}{c|}{ Sound intensity (dB) } \\
\cline { 2 - 10 } & $f$ & $V$ & $a$ & $f$ & $V$ & $a$ & $f$ & $V$ & $a$ \\
\hline 1 & $\mathbf{0 . 5 7 4 4}$ & 1.1072 & 0.9138 & $\mathbf{2 4 5 0}$ & $\mathbf{2 4 1 2}$ & $\mathbf{2 1 9 8}$ & $\mathbf{7 9 . 3}$ & 83.8 & 80.2 \\
\hline 2 & 0.9361 & 0.9722 & 1.3772 & 2733 & 2703 & 2541 & 80.6 & 80.1 & 82.7 \\
\hline 3 & 1.4467 & $\mathbf{0 . 8 7 7 7}$ & $\mathbf{0 . 6 6 6 1}$ & 2997 & 3064 & 3440 & 82.9 & $\mathbf{7 8 . 9}$ & $\mathbf{7 9 . 9}$ \\
\hline
\end{tabular}

\section{Tool Wear}

Hard turning aims to manufacture mechanical parts with good dimensional accuracy and surface quality with properties close to the grinding process. Generally, the surface roughness in the grinding process is smoother than $1.6 \mu \mathrm{m}$. This roughness can be used as a determining factor to evaluate crater wear. According to the previous studies (Čerče et al., 2015) and Standard ISO 3685, a crater wear depth of $0.3 \mathrm{~mm}$ is considered in this study as the ideal tool life criteria.

The efficiency in manufacturing can be improved by increasing the cutting speed. However, the high cutting speed generates a high temperature in the workpiece, tool and chip; hence the surface quality and the tool life are decreased.

Tool wear is a dominant parameter in the machining that affects manufactured component accuracy. The crater wear happens in the area of cutting edge. The amount of crater wear is calculated by measuring the crater wear region's width using an optical microscope having 220 times magnification. The width of crater wear is increased at the beginning of machining, and the growth of wear is decreased with time.

In order to evaluate surface roughness and crater wear during machining following cutting conditions were used; feed $(0.3 \mathrm{~mm} / \mathrm{rev})$, cutting speed $(150 \mathrm{~m} / \mathrm{min})$, and depth of cut $(0.7 \mathrm{~mm})$. The experimental results for surface roughness and crater wear with illustration at different intervals while turning hardened AISI 4140 employing multilayer-coated carbide $\left(\mathrm{TiCN} / \mathrm{Al}_{2} \mathrm{O}_{3} / \mathrm{TiN}\right)$ inserts are shown in Table 9. 
Table 9. Experimental results for surface roughness, crater wear, and their illustrations.

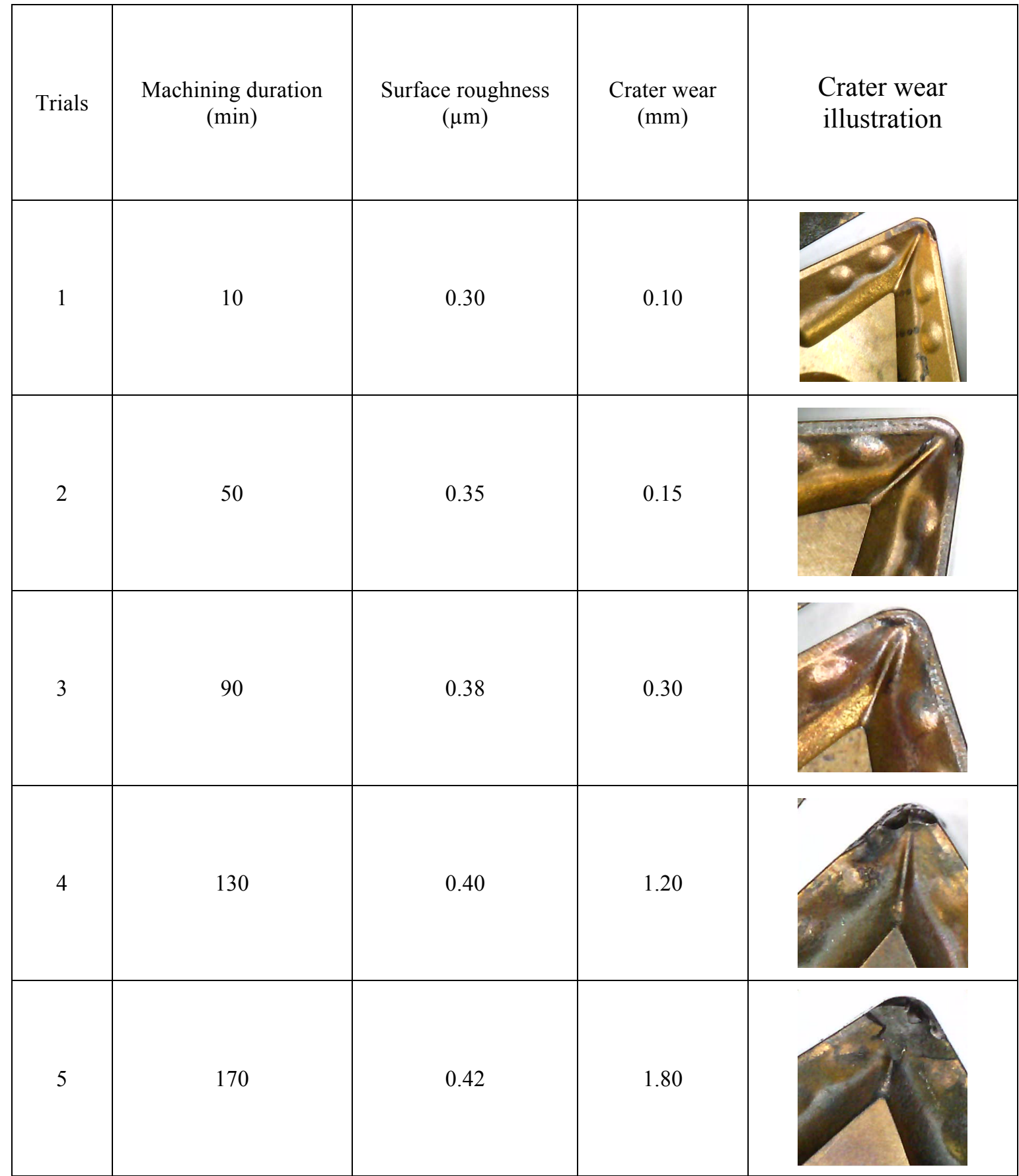

By progressing the machining, the cutting tool's sharpness degraded and resulted in a deterioration of the surface quality. The reason for the degradation of the tool sharpness and occurring the crater wear is the sliding of chips on the tool's rake surface. After $90 \mathrm{~min}$, the catastrophic failure of the tool has occurred due to crater 
wear caused by the collapse of the cutting edge. The variation of surface roughness and crater wear by cutting time is shown in Figures 5 and 6, respectively.

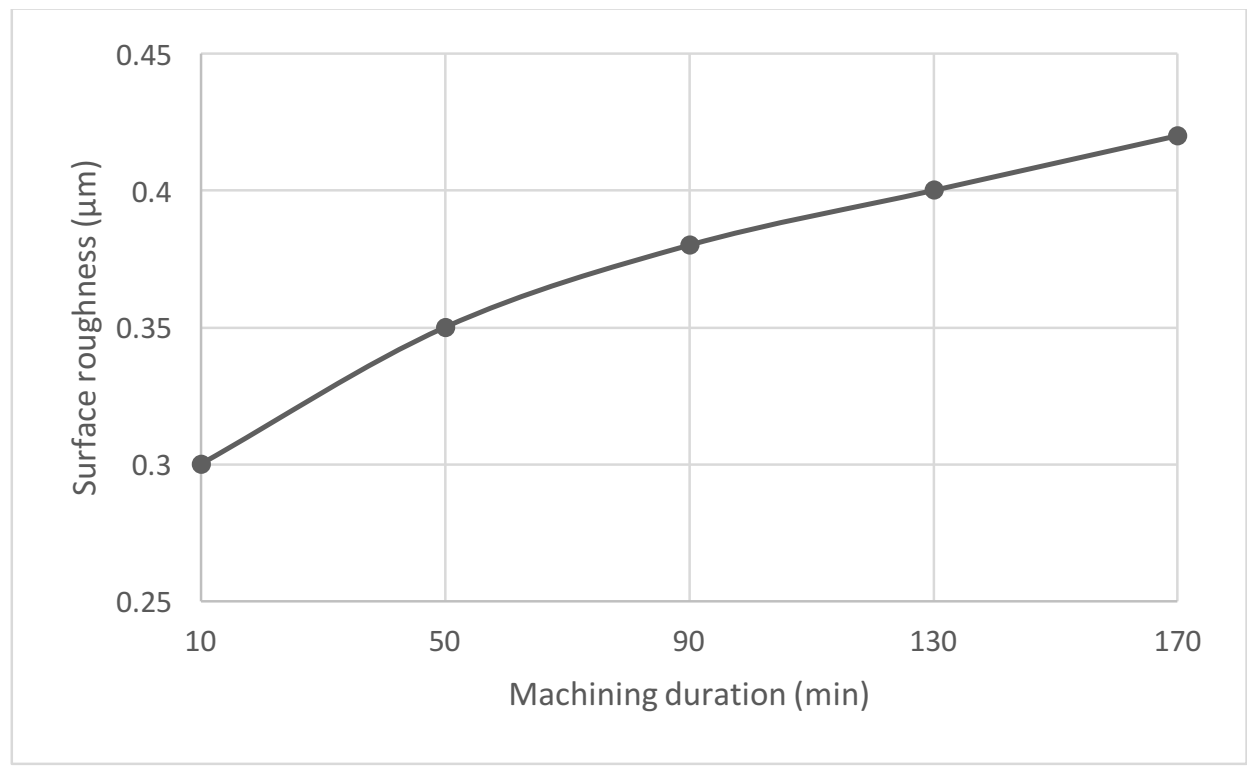

Figure 5. Variation of surface roughness with machining time.

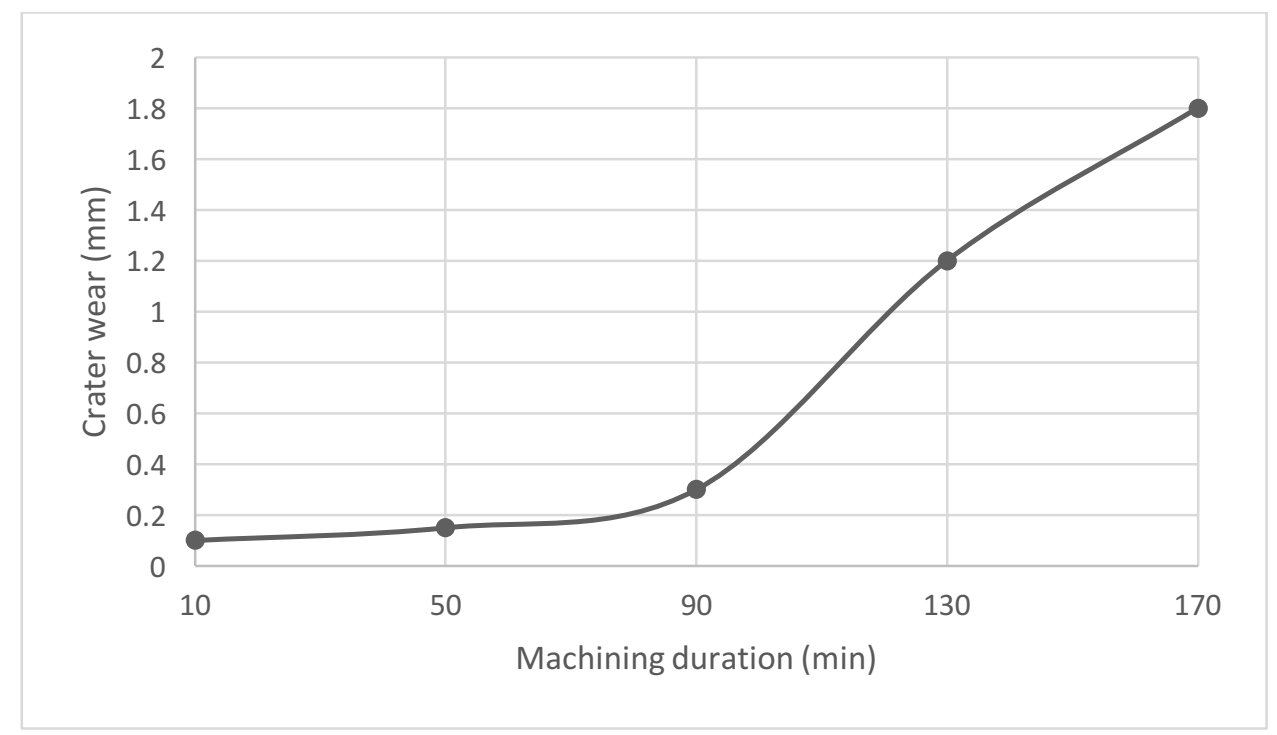

Figure 6. Variation of crater wear with machining time.

According to the results, the multilayer $\mathrm{TiCN} / \mathrm{Al}_{2} \mathrm{O}_{3} / \mathrm{TiN}$ coated carbide insert exposes good performance during hard turning of steel at high cutting speed. The titanium nitride (TiN) coated layer has the lubricity properties that decrease the friction between cutting inserts and workpiece; hence, it prevents the enhancement of temperature at higher cutting speed and consequently lags the growth of tool wear. Therefore, the increase in 
temperature is prevented at the contact surface and diffusion. Aluminum oxide $\left(\mathrm{Al}_{2} \mathrm{O}_{3}\right)$ layer exhibits good thermal barrier properties that decrease the tool wear. The titanium carbide nitride (TiCN) layer has good thermal stability and wear resistance. The TiN coating layer proposed good diffusion barrier properties. These properties increase the cutting tool material's chemical stability, thanks to the thermal barrier of the $\mathrm{Al}_{2} \mathrm{O}_{3}$ and diffusion barrier of the TiN while machining the hardened steel at higher cutting speed.

Figure 6 shows crater wear growth with cutting time for multilayer-coated carbide cutting tools during turning of hardened AISI 4140 under dry cutting conditions. The results showed that the crater wear creation is primarily affected by associated chemical wear and thermal conditions. The results indicated that tool wear progress by the time is due to abrasion at the rake face of the cutting tool. Any extreme crater wear causes a catastrophic failure of the tool due to the weakening of the cutting edge.

The growth of tool wear at the beginning of machining is slow due to the influence of $\mathrm{Al}_{2} \mathrm{O}_{3}$ layers as a thermal barrier, TiCN layer as wear resistance and a small amount of friction between tool and chip thanks to TiN lubricity properties. The barrier precluded heat from entering the cutting insert, and therefore a high amount of heat is dissipated by the chip.

The nature of TiN decreases the tool friction, whereas $\mathrm{TiCN}$ and $\mathrm{Al}_{2} \mathrm{O}_{3}$ reduce cratering. Multicoated layers present a combination of the properties of both types of coating in conjunction with various substrates. For example, the TiN layer over TiCN/Al2O3 coating remarkably enhances the coated cutting tool's crater resistance at both high and low machining speeds.

The slow growth of crater wear for multilayer-coated cutting tools presents stable machining without any premature tool failure by fracturing or chipping. According to table 8 , the crater wear was $0.1 \mathrm{~mm}$, nearly about $10 \mathrm{~min}$. Then, wear growth gradually and reaches to $0.15 \mathrm{~mm}$ in $50 \mathrm{~min}$. However, the tool reaches its limit value $(0.3 \mathrm{~mm})$ for nearly about $90 \mathrm{~min}$. The figures depict three wear zones for multilayer-coated carbide; initial wear, steady wear, and rapid wear that cause tool failure.

High temperature and pressure at cutting speed equal to or greater than $150 \mathrm{~m} / \mathrm{min}$ were the dominant factors in the rake face that cause the crater wear to occur near to cutting edge.

\section{Regression Model}

The mathematical models were developed for each response using a multiple linear regression model. The mathematical models for surface roughness, power consumption, and sound intensity are given in Equations 2, 3, and 4 , respectively. The coefficient of determination for surface roughness is $97.38 \%$. The power consumption and sound intensity were modelled with $99.47 \%$ and $97.33 \%$ accuracy, respectively.

$$
\text { Surface roughness }=-0.89+1.32 \mathrm{a}+0.0052 \mathrm{~V}+12.25 \mathrm{f}-0.0049 \mathrm{a} * \mathrm{~V}-6.65 \mathrm{a} * \mathrm{f}-0.0365 \mathrm{~V} * \mathrm{f}
$$

Power consumption $=2353-2580 \mathrm{a}-10.04 \mathrm{~V}-2180 \mathrm{f}+37.9 \mathrm{a} * \mathrm{~V}+4704 \mathrm{a} * \mathrm{f}+20.5 \mathrm{~V} * \mathrm{f}$

Sound intensity $=77.3+16.4 \mathrm{a}+0.0078 \mathrm{~V}+34.7 \mathrm{f}-0.147 \mathrm{a} * \mathrm{~V}+6.2 \mathrm{a} * \mathrm{f}-0.157 \mathrm{~V} * \mathrm{f}$ 
According to the previous studies, multilayer-coated carbide inserts have better performance compared to uncoated carbide inserts. Thus, the first and second-order regression models were developed for tool wear at a $95 \%$ confidence level based on machining time ( $\mathrm{T}$ ) as continuous predictors. The developed mathematical models for first- and second-order models are given in Equations 5 and 6, respectively.

$$
\begin{aligned}
& \text { Wear }=-0.291+0.01113 * \mathrm{~T} \\
& \text { Wear }=0.113-0.00374 * \mathrm{~T}+0.000083 * \mathrm{~T} * \mathrm{~T}
\end{aligned}
$$

The sufficiency of the developed regression model is confirmed through the coefficient of determination $\left(\mathrm{R}^{2}\right)$. The second-order model presents better variability of responses in predicting new results with $\mathrm{R}^{2}=97.49 \%$ compared to the first-order model with $\mathrm{R}^{2}=86.78 \%$. The second-order model has a higher $\mathrm{R}^{2}$ that indicates the available data fits perfectly with the model. Further, the confirmation test was performed, employing a secondorder model to compare the experimental value and predicted value. The minimum and maximum residuals were 0.016 and 0.171 , respectively. The predicted and experimental values for tool crater wear by employing the second-order model are presented in Table 10.

Table 10. The predicted and experimental values for tool crater wear.

\begin{tabular}{|c|c|c|c|}
\hline Time (min) & Predicted value (mm) & Experimental value (mm) & Residuals \\
\hline 10 & 0.084 & 0.10 & 0.016 \\
\hline 50 & 0.134 & 0.15 & 0.016 \\
\hline 90 & 0.449 & 0.30 & -0.149 \\
\hline 130 & 1.029 & 1.20 & 0.171 \\
\hline 170 & 1.876 & 1.80 & -0.076 \\
\hline
\end{tabular}

\section{CONCLUSION}

The impacts of cutting depth, cutting speed, and feed rate on the surface roughness, power consumption, sound intensity, and tool wear are investigated in this study while turning hardened AISI 4140 using multilayercoated carbide insert under dry cutting condition. Also, the high values of cutting depth and feed rate were selected to evaluate their effect on the sound intensity and power consumption. The results of this experimental study are presented as follows:

According to the analysis of variance, the feed rate has a dominant effect on surface roughness by $42.30 \%$ contributions. Following feed rate, depth of cut shows a significant impact on the surface roughness by $28.70 \%$ contribution. In addition, the effect of $(\mathrm{a} * \mathrm{f})$ on the surface quality is significant, with a $17.66 \%$ contribution. However, the cutting speed has a minor effect on surface roughness.

The depth of cut with $64.83 \%$ contribution considerably influences the power consumption. The motor current increases by enhancing the depth of cut; hence, the consumed energy by the lathe machine also increases. Following the depth of cut, cutting speed and feed exhibit great effect on power consumption with $16.81 \%$ and $11.80 \%$ contribution, respectively. 
Cutting speed is the dominant factor that affects sound intensity by $45.06 \%$ contribution. Increasing the cutting speed decreases the sound intensity simultaneously. The feed rate is the next significant factor in sound intensity, with a $24.00 \%$ contribution. Any increase in the feed rate increases the sound intensity. Finally, the depth of cut with a $16.97 \%$ contribution presents an essential impact on the response.

Except for two combinations for multilayer-coated carbide inserts, the rest of the surface roughness values are less than $1.6 \mu \mathrm{m}$; this is among the recommended range for hard turning. However, for evaluating the tool wear, only a combination of $(0.3 \mathrm{~mm} / \mathrm{rev})$ feed, $(150 \mathrm{~m} / \mathrm{min})$ cutting speed, and $(0.7 \mathrm{~mm})$ depth of cut is taken into account, and the maximum surface roughness is calculated as $(0.42 \mu \mathrm{m})$.

According to the results, multilayer-coated carbide inserts $\left(\mathrm{TiCN} / \mathrm{Al}_{2} \mathrm{O}_{3} / \mathrm{TiN}\right)$ exhibit good performance in terms of tool wear due to the layers' good properties. $\mathrm{TiCN}$ layer has wear resistance, whereas $\mathrm{Al}_{2} \mathrm{O}_{3}$ layers act as a thermal barrier, and TiN presents lubricity properties that reduce friction between tool and workpiece. The experimental results show that tool crater wear for multilayer-coated carbide inserts was $0.10 \mathrm{~mm}, 0.15 \mathrm{~mm}$, and $0.30 \mathrm{~mm}$ after $10 \mathrm{~min}, 50 \mathrm{~min}$, and $90 \mathrm{~min}$, respectively. The tool life criterion was assumed to be $0.30 \mathrm{~mm}$ based on previous studies. At higher cutting speed and as time passes, the inserts' coating is wiped out, and chipping occurs at the cutting edge and leads to tool wear. Thus, tool crater wear started to be greater than $0.30 \mathrm{~mm}$ after $90 \mathrm{~min}$, and catastrophic failure occurred.

The results indicated that the second-order regression model exhibits better performance with $\mathrm{R}^{2}=97.49 \%$ to predict the multilayer-coated carbide tool wear during hard turning of AISI 4140 steel. Also, the second-order regression model has good adequacy due to close results between the experimental value and predicted value for the crater wear of multilayer-coated carbide inserts.

The accuracy of proposed mathematical models for predicting the power consumption, sound intensity, and surface roughness is in good agreement with actual data with $\mathrm{R}^{2}=99.47 \%, \mathrm{R}^{2}=97.33 \%$, and $\mathrm{R}^{2}=97.38 \%$, respectively. In order to reduce power consumption, the first level of all machining parameters should be selected. Minimization of surface roughness can be done by increasing the cutting speed and decreasing the feed rate according to materials theory machining.

\section{REFERENCES}

Asiltürk, I., \& Akkuş, H. 2011. Determining the effect of cutting parameters on surface roughness in hard turning using the Taguchi method. Measurement, 44 (9): 1697-1704.

Aslantas, K., Ucun, I., \& Cicek, A. 2012. Tool life and wear mechanism of coated and uncoated A12O3/TiCN mixed ceramic tools in turning hardened alloy steel. Wear, 274: 442-451.

Bartarya, G., \& Choudhury, S. K. 2012. State of the art in hard turning. International Journal of Machine Tools and Manufacture, 53 (1): 1-14.

Bouacha, K., Yallese, M. A., Mabrouki, T., \& Rigal, J. F. 2010. Statistical analysis of surface roughness and cutting forces using response surface methodology in hard turning of AISI 52100 bearing steel with CBN tool. International Journal of Refractory Metals and Hard Materials, 28 (3): 349-361.

Čerče, L., Pušavec, F., \& Kopač, J. 2015. 3D cutting tool-wear monitoring in the process. Journal of Mechanical Science and Technology, 29 (9): 3885-3895.

Das, S. R., Panda, A., \& Dhupal, D. 2018. Hard turning of AISI 4340 steel using coated carbide insert: Surface roughness, tool wear, chip morphology and cost estimation. Materials Today: Proceedings, 5 (2): 6560-6569. 
Elbah, M., Yallese, M. A., Aouici, H., Mabrouki, T., \& Rigal, J. F. 2013. Comparative assessment of wiper and conventional ceramic tools on surface roughness in hard turning AISI 4140 steel. Measurement, 46 (9): 3041-3056.

Guo, Y. B., \& Liu, C. R. 2002. Mechanical properties of hardened AISI 52100 steel in hard machining processes. Journal of manufacturing science and engineering, 124 (1): 1-9.

Huang, Y., \& Dawson, T. G. 2005. Tool crater wear depth modeling in CBN hard turning. Wear, 258 (9): 1455-1461.

Huang, Y., \& Liang, S. Y. 2004. Modelling of CBN tool crater wear in finish hard turning. The International Journal of Advanced Manufacturing Technology, 24 (9-10): 632-639.

Keblouti, O., Boulanouar, L., Azizi, M. W., \& Yallese, M. A. 2017. Effects of coating material and cutting parameters on the surface roughness and cutting forces in dry turning of AISI 52100 steel. Structural Engineering and Mechanics, 61 (4): 519-526.

Kuntoğlu, M., \& Sağlam, H. 2019. Investigation of progressive tool wear for determining of optimized machining parameters in turning. Measurement, 140: 427-436.

Kurniawan, D., Yusof, N. M., \& Sharif, S. 2010. Hard machining of stainless steel using wiper coated carbide: tool life and surface integrity. Materials and Manufacturing Processes, 25 (6): 370-377.

Meddour, I; Yallese, MA; Khattabi, R; Elbah, M; Boulanouar, L. 2015. Investigation and modeling of cutting forces and surface roughness when hard turning of AISI 52100 steel with mixed ceramic tool: cutting conditions optimization. The International Journal of Advanced Manufacturing Technology, 77 (5-8): 1387-1399.

Mia, M., Dey, P. R., Hossain, M. S., Arafat, M. T., Asaduzzaman, M., Ullah, M. S., \& Zobaer, S. T. 2018. Taguchi $\mathrm{S} / \mathrm{N}$ based optimization of machining parameters for surface roughness, tool wear and material removal rate in hard turning under MQL cutting condition. Measurement, 122: 380-391.

Moganapriya, C., Rajasekar, R., Ponappa, K., Venkatesh, R., \& Jerome, S. 2018. Influence of coating material and cutting parameters on surface roughness and material removal rate in turning process using Taguchi method. Materials Today: Proceedings, 5 (2): 8532-8538.

Motorcu, A. R. 2010. The optimization of machining parameters using the Taguchi method for surface roughness of AISI 8660 hardened alloy steel. Journal of Mechanical Engineering, 56 (6): 391-401.

Noordin, M. Y., Kurniawan, D., \& Sharif, S. 2007. Hard turning of stainless steel using wiper coated carbide tool. International Journal of Precision Technology, 1 (1): 75-84.

Nouari, M., List, G., Girot, F., \& Coupard, D. 2003. Experimental analysis and optimisation of tool wear in dry machining of aluminium alloys. Wear, 255 (7-12): 1359-1368.

Patel, V. D., \& Gandhi, A. H. 2019. Analysis and modeling of surface roughness based on cutting parameters and tool nose radius in turning of AISI D2 steel using CBN tool. Measurement, 138: 34-38.

Rakesh, M., \& Datta, S. 2019. Effects of cutting speed on chip characteristics and tool wear mechanisms during dry machining of Inconel 718 using uncoated WC tool. Arabian Journal for Science and Engineering, 44(9): 7423-7440.

Şahinoğlu, A., \& Rafighi, M. 2020a. Investigation of Vibration, Sound Intensity, Machine Current and Surface Roughness Values of AISI 4140 During Machining on the Lathe. Arabian Journal for Science and Engineering, 45 (2): 765-778.

Şahinoğlu, A., \& Rafighi, M. 2020b. Optimization of cutting parameters with respect to roughness for machining of hardened AISI 1040 steel. Materials Testing, 62 (1): 85-95. 
Sahoo, A. K., \& Sahoo, B. 2012. Experimental investigations on machinability aspects in finish hard turning of AISI 4340 steel using uncoated and multilayer coated carbide inserts. Measurement, 45 (8): 2153 2165 .

Salimi Asl, A., Erdem, A., \& Rafighi, M. 2017. Applying a multi sensor system to predict and simulate the tool wear using of artificial neural networks. Scientia Iranica, 24 (6): 2864-2874.

Salimi Asl, A., \& Rafighi, M. 2017. Titreşim ve Kesme Kuvveti Esaslı Takım Aşınmasının Bulanık Mantıkla İzlenmesi ve Tahmini. Politeknik Dergisi, 20 (1): 111-120.

Salimi Asl, A., \& Rafighi, M. 2017. Talaş Kaldırma İşlemlerinde Takım Durumunun İzlemesi İçin Son Gelişmelerin İncelenmesi. Düzce Üniversitesi Bilim ve Teknoloji Dergisi, 5 (1): 314-337.

Sarnobat, S. S., \& Raval, H. K. 2019. Experimental investigation and analysis of the influence of tool edge geometry and work piece hardness on surface residual stresses, surface roughness and work-hardening in hard turning of AISI D2 steel. Measurement, 131: 235-260

Tönshoff, H. K., Arendt, C., \& Amor, R. B. 2000. Cutting of hardened steel. Cirp Annals, 49 (2): 547-566.

Yallese, M. A., Chaoui, K., Zeghib, N., Boulanouar, L., \& Rigal, J. F. 2009. Hard machining of hardened bearing steel using cubic boron nitride tool. Journal of materials processing technology, 209 (2): $1092-$ 1104.

Zhao, J., \& Liu, Z. 2020. Influences of coating thickness on cutting temperature for dry hard turning Inconel 718 with PVD TiAlN coated carbide tools in initial tool wear stage. Journal of Manufacturing Processes, 56: 1155-1165 